\title{
La dimensión histórica de la poética de la ficción de Ricardo Palma
}

\author{
Jorge Valenzuela Garcés \\ Universidad Nacional Mayor de San Marcos \\ jorgevalenzuela4@hotmail.com \\ Lima-Perú
}

\section{Resumen}

Este artículo se propone responder a ciertas preguntas relacionadas con la poética de la ficción palmiana: ¿Qué pensaba Ricardo Palma de la ficción como acto de la imaginación y la fantasía? ¿Qué implicancias tenía el que considerara a la ficción como un instrumento que lo vinculaba al registro documental y al pasado? ¿Qué ponía en evidencia Palma en sus Tradiciones con respecto a la relación entre ficción, historia y memoria? Se incide en la poética de la ficción palmiana y en su carácter popular. Utilizamos como marco teórico las propuestas de Ana María Amar Sánchez en su libro El relato de los hechos.

Palabras claves: Ricardo Palma, Ficción, Poética, Tradiciones peruanas.

\begin{abstract}
This article intends to answer certain questions related to the poetics of the fiction of Ricardo Palma: What did he think about fiction as an act of imagination and fantasy? What implications did he consider fiction as an instrument that linked him to the documentary record and the past? What did Palma show in his Traditions regarding the relationship between fiction, history and memory? The poetics of the fiction of Palma and its popular character are emphasized. We use as a theoretical framework the proposals of Ana María Amar Sánchez in her book El relato de los hechos.
\end{abstract}

Keywords: Ricardo Palma, Fiction, Poetics, Peruvian Traditions. 
Jorge Valenzuela Garcés (Perú): Es uno de los más destacados integrantes de la generación de narradores peruanos de los ochenta. Ha publicado cinco libros de cuentos Horas contadas (1988), La soledad de los magos (1994), La sombra interior (2006), Juegos secretos (2011) e Infiernos mínimos (2014). Ha obtenido reconocimientos en el Premio Copé de Cuento y en el José María Arguedas. Dirige, desde hace 20 años, el Taller de Narración de San Marcos. A nivel académico es doctor en Literatura Hispanoamericana por la Universidad Complutense de Madrid y profesor Principal del Departamento de Literatura de la Facultad de Letras y Ciencias Humanas de la UNMSM. Es investigador del Sistema Nacional de Ciencia, Tecnología e Innovación Tecnológica (SINACYT). Ha sido profesor visitante en las universidades de São Paulo, Concepción, en Chile y en La Habana. Ha obtenido el Premio al Mérito Científico otorgado por el Vicerrectorado de Investigación en 2014. Como crítico literario ha publicado un Manual de Literatura Hispanoamericana $(2009,2011)$ en dos volúmenes; El mundo de los clásicos. Lecturas de Rodó, Stuart Mill y Vargas Llosa (2012); Principios comprometidos. Mario Vargas Llosa entre la literatura y la política (2013), La ficción y la libertad. Cuatro ensayos sobre la poética de la ficción de Mario Vargas Llosa (2017) y Narración. 50 años después (2018) además de artículos de su especialidad en revistas peruanas y del extranjero. 


\section{Introducción}

En las palabras de presentación de su conocida serie titulada "Hilachas", Palma se refiere al conjunto de textos que la conforman como una mezcla de "apuntaciones históricas y chismografía de viejas". Esta anotación resulta importante porque nos vincula con un aspecto central de su poética de la ficción: su carácter híbrido, esa permanente intersección entre la historia y la invención, elemento este último que le sirve para alejarse del referente real y recrear, exagerar y hasta deformar la base documental, y que busca, entre otros impactos, el del humor. Además de considerarla como producto de este diálogo con la historia, Palma se refiere, en otro lugar, a que la tradición es "una de las formas que puede revestir la historia, pero sin los escollos de esta”.

La posibilidad de que la historia puede ser contada como lo hace Palma en sus tradiciones abre un campo para la reflexión. Supone, en primer término, reconocerle al discurso histórico cierta flexibilidad y apertura al diálogo con la imaginación y la fantasía. Este aserto, desde luego, tiene consecuencias. Implica reconocer un hecho: que la historia pueda ampliar las limitaciones que supone su tan mentada objetividad y, por ello, su confiabilidad. Si a ello le sumamos aquellos "escollos" que Palma le atribuye al discurso histórico, se hace más evidente que, para el escritor limeño, una de las funciones de la ficción es relajar el discurso oficial otorgándole una vitalidad de la que carece. ¿A qué escollos se refiere Palma? Sin duda a los de la recepción del texto histórico por un público no familiarizado con la solemnidad y desafección con que era escrita y a una retórica fría que podía desanimar al más entusiasta de los lectores.

Las posibilidades de una escritura que se inspire en un hecho realmente acaecido o referido en una fuente confiable, pero que, simultáneamente, sea tratado, a partir de su abierta 
manipulación, con los recursos de la fantasía y humor, es todo un logro en un momento en el que la historia se postula como un discurso hegemonizador ${ }^{1}$ a partir del apoyo que recibe de los mecanismos implementados por el método experimental, la investigación científica y el manejo solvente de las fuentes. Supone también enfrentarse a la hegemonía y prestigio del discurso histórico hilvanando una discursividad alternativa y crítica a partir de los recursos de la ficción. Por ello Palma sostiene, también, que "La tradición no es precisamente historia, sino relato popular, y ya se sabe que para mentiroso el pueblo" 2 .

A partir de esta afirmación puede sostenerse que Palma tenía una conciencia clara con respecto a que la historia era una forma de discurso que, en el Perú, jugaba a favor de la ficción, sobre todo por la profusión de hechos de carácter sobrenatural, extraño, fantástico y milagroso que infestaba todo el soporte documental de la Colonia. En efecto, Palma advierte, entre otros aspectos de nuestra realidad, el carácter desmesurado y ridículo de la santidad y la violencia política del sistema de dominación y sus singulares protagonistas, referidos en los textos de sacerdotes, historiadores y cronistas. Además, advierte el carácter tragicómico que nos signa como nación. Por ello no hace más que profundizar en la ficcionalidad de nuestra historia, haciendo evidente su carácter irreal, denunciando su desproporcionada manipulación y su efectivo papel en el objetivo de fortalecer el control social del virreinato sobre la masa indígena y criolla.

Además, algo importante: Palma descubre que el pasado es cambiante, que la memoria (aquello que es recuperado del pasado de forma problemática) se ve afectada inevitablemente

l Con respecto a este punto conviene consultar el artículo de Aníbal González sobre el carácter antigenealógico de la tradición palmiana. Ver bibliografía.

2 Esto lo dice Palma en una carta a Alberto Larco Herrera, escrita en 1907. 
por las dinámicas del recuerdo y que, por ello, no es fija, ya que siempre supone una apropiación del sujeto cognoscente de acuerdo a sus intereses y punto de vista. Palma demuestra que el pasado puede ser decodificado de diversas formas $y$, al vincular historia y ficción, lo que hace es reapropiarse del pasado insertándolo en un nuevo contexto en el que ese pasado puede decirnos más de lo que el simple documento podría decir.

\section{La poética de la ficción de Ricardo Palma}

Se equivocan quienes quieren ver en Palma a un historiador, cronista o periodista. No lo es. Es, esencialmente, un escritor de ficción que atiende y altera la base documental ${ }^{3}$ que le proporciona la historia para hacer literatura. Y si bien Palma comprende la discursividad de la historia y sus procedimientos legitimadores (asociados a una determinada visión del pasado) solo lo hace con el fin de cuestionar su influencia y poder. Teniendo en cuenta estos presupuestos mínimos, creo que el proyecto escritural de Palma se hace más comprensible.

Aunque Palma no llegó a formalizar una poética de la ficción, sí llegó a definir lo que era una tradición. En la definición llega a sostener que esta "no es más que una de las formas que puede revestir la historia”. Esta definición, que tendrá diversos matices a lo largo del tiempo, atiende a dos aspectos que pueden servirnos como punto de partida para establecer las relaciones que Palma mantenía con el concepto de ficción. El primer aspecto tiene que ver con las posibilidades estéticas del discurso histórico, con su capacidad para ser permeable a las demandas de un diálogo creativo con la imaginación y la fantasía. El segundo, con que su concepto de ficción estuviese

3 Revisar, sobre este punto, el interesante y polémico artículo de Roberto Reyes que ubica a Palma como precursor de la narrativa de no ficción. Ver bibliografía. 
anclado en la explotación del hecho realmente acaecido, referido o documentado, como sucede con los contenidos de la historia, la crónica, la biografía o, simplemente, la noticia.

Palma descubre las posibilidades estéticas de lo documental en estricta relación con la historia cuando pone en contacto al archivo ${ }^{4}$ con la ficción. Entiende que el discurso histórico es un artefacto literario construido con documentos o noticias y que, en su construcción, es tan ficcional como el discurso literario. En efecto, entiende que el discurso de la historia es una construcción tan afectada por los recursos de la ficción que no ve inconveniente en literaturizarlo. Palma es consciente que la historia es narración, que supone un punto de vista, un manejo del tiempo, la construcción de un marco narrativo, la interrelación de personajes, la disposición de secuencias, una trama y que dentro de ella suceden acontecimientos, como en los relatos de ficción.

Pero, ipor qué ficcionalizar el documento o, en suma, la historia? En primer término, Palma advierte que la historia en el Perú constituye nuestra memoria política sobre la base de relatos o anécdotas y que esa memoria es importante en los procesos de legitimación del poder virreynal, poder que desde su condición liberal cuestiona desde la raíz. De allí su interés por reescribir los contenidos del archivo desde la perspectiva popular, perspectiva que se quiere menos formal, más animada, menos lejana, más humana, más próxima. En segundo término, Palma comprende que la ficcionalización de la historia le otorga al documento histórico una dimensión y utilidad que de otro modo no tendría. En efecto, entiende que la elección de anécdotas o hechos vinculados con el pasado es esencial en la construcción de una identidad nacional, una identidad común

4 El concepto ha sido desarrollado por González Echevarría en su conocido libro Mito y archivo. Ver bibliografía. 
más democrática, resultado de una visión irreverente e irónica del pasado colonial. En este caso, la ficción debía cumplir con hacer importante una serie de personajes y hechos que nos permitiesen comprender, desde nuestra condición de lectores aun no afincados en una tradición democrática ${ }^{5}$, el carácter absurdo, y extravagante de la Colonia. El semblante irónico de la ficción palmiana, de este modo, busca dejar una marca en nosotros como sujetos y operar sobre nuestra perspectiva histórica con el propósito de desarrollar una mirada personal con respecto a ese pasado, es decir, busca construir ciudadanos críticos. La ficción palmiana nos permite reír y criticar, sopesar el sinsentido del poder, la delgadez de lo sagrado, la flaqueza de la autoridad, acercarnos con las armas del humor y con una conciencia del ridículo a un sistema de dominación que rechazamos a través de la sonrisa inteligente.

Palma logra que los medios de la ficción nos acerquen al pasado y constituyan una memoria activa que nos permita observar el presente, pero sobre todo el futuro sin el aparato del discurso histórico, desmontando como sostiene Aníbal González "el andamiaje genealógico del historicismo decimonónico, andamiaje sobre el cual el poder instituido (los descendientes de la colonia, una aristocracia antañona y reaccionaria) pretendía asentar sus reclamos de autoridad y de dominio" (1993, p. 474).

Inficionar a la historia de ficción supone agrietar las paredes de un castillo, el de la historiografía tradicional, que se erigía indestructible en pleno siglo XIX. A través de la ficción Palma cuestiona y relativiza el pasado empleando una conformación textual (la tradición) cuya hibridez, precisamente, busca poner

5 Este aspecto es fundamental para entender el proyecto literario de Palma. Con sus tradiciones construye a un lector irreverente en múltiples sentidos. Desarrolla un lector irónico, con una capacidad para cuestionar el sinsentido de la historia y con un deseo de búsqueda de justicia. Con ello logra desestabilizar los intereses de un segmento social supérstite vinculado a la Colonia. 
en cuestión el instrumental genérico discursivo en el que el poder colonial se sustentaba. Al romper las paredes que situaban a los géneros literarios en compartimentos estancos, Palma destruye la base discursiva de un segmento social vinculado con la reivindicación de derechos que buscaban regresar al Perú de la Colonia.

\section{El proceso de ficcionalización palmiano}

En su libro El relato de los hechos Ana María Amar Sánchez hace referencia al proceso de ficcionalización que atraviesan los textos que "respetan" los documentos en los que se basan (1992, p. 47). Su aproximación puede servirnos para entender el modo en que Palma se acerca a la historia y al registro documental.

El proceso se inicia con "la subjetivación de las figuras provenientes de lo real que pasan a constituirse en personajes y narradores" $(1992,47)$. Esto implica que, de manera inevitable, los personajes y narradores de los textos se ficcionalizan a través de un proceso de individualización, es decir, de un acercamiento que nos permite conocer su interioridad y aspectos que son imposibles de observar si no es a partir de la recreación ficcional que se manifiesta, usualmente en Palma, a partir del empleo del estilo indirecto libre y la administración de información narrativa sin restricciones. Lo mismo sucede con el narrador que, en el caso de las Tradiciones peruanas, muestra las evidencias de su carácter ficcional a partir de un modo de enunciación que tiende a retorizarse debido al empleo recurrente de ciertos recursos como la narración coloquializada o la apelación a un narratario intratextual que cumple con reforzar la perspectiva conversacional con que es narrado el hecho.

Como consecuencia del proceso de subjetivación de los elementos provenientes de lo real tenemos, según Ana 
María Amar, una segunda consecuencia: la politización de la perspectiva desde la que se cuenta, (1992, p. 47), que afecta tanto a la mirada del narrador, ya ficcionalizado a través de los recursos mencionados, como de los personajes, cuya actuación e interioridad revelan un modo de inserción en el mundo. En el caso del narrador palmiano esta politización se manifiesta a partir de una ironización general del discurso que evidencia una posición irreverente con respecto al periodo colonial y a su rancia tradición. Citemos como ejemplo un fragmento de la ácida tradición "Un litigio original":

La guerra era, digámoslo así, de casa a casa: asunto de pergaminos más o menos amarillentos, y de un arminio, roel o dragante de más o de menos en el escudo de armas (Palma, 1961, p. 488)

Este narrador, además de ironizar, ficcionaliza la anécdota a partir de un lenguaje que aleja los hechos de la objetividad, poniendo el acento en las deformaciones y exageraciones, a partir de la explotación del nivel connotativo del lenguaje.

Este proceso, que supone una reescritura de la anécdota referida en los archivos, está mediado por un marco literario y un esquema dentro del cual se vierte el contenido de los hechos. La construcción de una dimensión espacio temporal en la que la profundidad de la historia y el dato real compiten por otorgarle verosimilitud a lo contado, completan la ficción histórica palmiana. Citemos de la misma crónica:

Entre el segundo marqués de Santiago D. Dionisio Pérez Manrique y Villagrán y el primer conde de Sierrabella D. Cristóbal Mesía y Valenzuela había, por los tiempos del virrey conde de la Monclova, una enemistad de mil demonios" (Palma, 1961, p. 488). 
Palma fue consciente, desde su condición de reescritor ${ }^{6}$, que la literatura era un ejercicio del lenguaje y que, como sostiene Amar Sánchez, los "hechos existen en la medida en que son contados" (1992, p. 34), es decir, en tanto son narrativizados a partir de una estrategia que busca producir en el lector una serie de efectos que, en el caso de Palma, se alimentan del humor y la ironía. La reescritura a la que Palma sometió la historia pública y privada del Perú demuestra que su concepción de la verdad histórica estaba marcada a fuego por la relatividad y que, por ello, podía ser tratada literariamente; que no hay una verdad previa detrás de las palabras, sino que esta verdad, si la hay, es el resultado de un proceso constructivo. Su concepción de la ficción pasaba por confrontar su versión personal de los hechos con la oficial, adoptando los modos de lo popular, lo conversacional y lo oral, y haciendo que la historia, el pasado, se democratice a partir de su exposición y crítica.

La ficción en Palma plantea de entrada una renuncia a los modos del realismo ingenuo ${ }^{7}$, en un momento en el que, precisamente, esta escuela venía postulando la posibilidad de llegar a conocer la verdad objetiva gracias a la ciencia y a su método científico. Palma se confronta con la ficción realista y sus presupuestos al destruir la idea de que la literatura podía generar un texto sin mediaciones, objetivo, autónomo. La propia reescritura como mecanismo de producción textual evidencia una conciencia mediadora en la generación de textos ficcionales, por lo tanto, lo que plantea su poética, no es ocultar el procedimiento

6 La categoría de reescritor puede ser muy productiva al momento de acercarnos a escritores que hacen explícito el carácter hipertextual de su obra. Borges es uno de los ejemplos más notables de esta práctica en la que la apropiación de fuentes diversas, resulta ser el mecanismo de producción textual predominante.

7 Entiéndase que el modo de representación palmiano es realista por su apego a un universo reconocible por el lector, pero que no lo es en tanto hace evidente los modos de producción textual en los que se inserta. Para el lector queda claro que la realidad referida es una realidad artificial, construida de segunda mano. 
ficcionalizador que emplea al escribir, sino exhibirlo. De este modo, en el caso de Palma, su concepto de ficción destaca por situar a la forma en el primer plano de la creación, forma que implica "una toma de posición activa con respecto al contenido" (Amar, 1992, p. 37). La forma de la ficción, entonces, en Palma, evidencia una relación conflictiva con otras formas del discurso, empezando por el propiamente literario y luego el histórico, para ubicarse en un ámbito cuya hibridez resulta todo un desafío para la ciudad letrada cuyo poder se sustentaba en el discurso histórico tradicional.

Así, Palma, abre las compuertas de la ficción que, desde su ejercicio se politiza, es decir, se convierte en un instrumento que desmonta el andamiaje de la dominación colonial desde un cuestionamiento de la discursividad histórica en la que aquella fundamentaba su poder.

\section{La ficción palmiana y lo popular}

Vincular la ficción al registro de lo popular es otro aspecto importante en la poética de la ficción palmiana. Al denominar "relato popular" a la tradición, Palma destaca y refuerza dos aspectos que resultan esenciales en su práctica escritural. El primero, relacionado con la recuperación de la capacidad creativa del pueblo, esa capacidad para dotar a un relato de potencia y fuerza y, por lo tanto, de esa afilada y fecunda imaginación que se encuentra de manera espontánea en la comunidad, y cuya función es, normalmente, crítica. Para Palma, la ficción que no se alimenta de la imaginación y la fantasía populares no es ficción. Para el tradicionista, la ficción debía impregnarse de la forma espontánea y natural en que aquellas se consolidaban. Para Palma -insistimos- la ficción adopta los modos de lo popular o no es ficción. Es más, en lo popular encuentra el verdadero sentido de su praxis. Palma encuentra esa capacidad 
recreativa, esa capacidad de mentir con conocimiento de causa (a la que alude en varias oportunidades) en las calles, en los corros de una Lima en la que el discurso de la calle es decisivo al momento de forjar prestigios o echarse abajo una reputación.

Este hecho, desde luego, es el producto de una poética de la ficción que reconoce el carácter inestable del discurso, un discurso (la tradición) que se postula abiertamente como la recreación de un contenido que busca recuperar la animada distorsión con que el pueblo asume y procesa la narración de una anécdota. Cuando Palma hace referencia a que sus textos son también "chismografías de viejas" está reconociendo esa dimensión en la que un suceso realmente acaecido se exagera o deforma y trasmite una fuerte crítica social. Reconoce, por lo tanto, que el propio discurso histórico pudiera estar influido por esa fuente popular. Entonces, ino es coherente restituirle al documento base esa dimensión que los propios historiadores se ocuparon de cercenar de acuerdo a sus propios intereses? La voz del narrador absolutamente coloquializada en las Tradiciones peruanas adelanta un aspecto de la creación literaria que, lamentablemente, no fue seguida por nuestra narrativa académica y formal. La implementación de un narrador que asume lo popular como propio y que logra desaparecer la distancia entre el punto de vista y el mundo referido en el texto, recién vuelve a surgir en los años sesenta del siglo XX bajo los imperativos literarios del Grupo Narración.

El segundo aspecto tiene que ver con el modo en que esa imaginación popular es canalizada. En este sentido, la elección de una escritura impregnada de una fuerte coloquialidad constituye, en el caso de Palma, una elección literaria, pero sobre todo política. Lo coloquial, lo conversacional nos acerca a lo espontáneo, a lo natural. Por ello debemos observar al recurso de lo coloquial como un medio que busca democratizar lo literario. 
Afectar al discurso de coloquialidad es recuperar la dimensión de la oralidad popular, es volver a la génesis del discurso, a su origen prístino y poderoso. Palma insiste en el hecho de oralizar la escritura con el propósito de mantener viva la presencia de la voz popular a través de un narrador que se manifiesta como perteneciente a esa entidad que podemos llamar pueblo. Palma logra, además, gracias a lo coloquial, poner en evidencia las limitaciones de la escritura histórica, desentendida del efecto de la voz. Limitada en su origen a ser un medio para la conservación de hechos, datos, efemérides o estadísticas, la escritura histórica, cuando se impregna de lo coloquial, logra una gran vitalidad, consigue trasladar al lector a la realización del hecho mismo, situarlo en medio de la fuerza de los sentimientos humanos y de estados de ánimo. En suma, arranca al pasado de su condición anacrónica, y activa y potencia su significación en un diálogo con el presente.

\section{Conclusiones}

1. Palma ficcionaliza la historia con un propósito claro: cuestionar el discurso histórico oficial y deshegemonizar, desde la literatura, su influencia en un contexto en el que las formas de pensamiento colonial aún persistían como mecanismos de control político y social en América Latina.

2. Palma logra mostrar, a través de sus Tradiciones peruanas, la diferencia entre historia y literatura, y deja en claro que son dos formas opuestas de entender discursivamente el mundo.

3. A través de la ficcionalización de la historia, Palma evidencia la manipulación de todo discurso y desmonta los principios del realismo ingenuo.

4. Para Palma, la ficción es el único medio que nos permite escapar de la dominación ideológica propugnada por el discurso 
histórico y nos permite alcanzar, por la imaginación y la fantasía, aquello que entendemos por libertad crítica y democracia.

5. La ficción para Palma debe hacer evidente su dimensión social a partir de la oralización del lenguaje. En este sentido, entiéndase que las tradiciones de Palma son textos que fueron escritos para ser leídos en voz alta. De este modo, Palma logra devolver a la narrativa de ficción a su lugar de origen: el pueblo.

\section{Bibliografía}

Amar Sánchez, A. M. (1992). El relato de los hechos. Buenos Aires: Beatriz Viterbo editora.

González, A. (1993). "Las tradiciones entre la historia y el periodismo". En Julio Ortega (edición crítica), Tradiciones peruanas. Madrid: ALLCA, Colección Archivos, pp. 459-477.

González Echevarría, R. (2000). Mito y archivo: Una teoría de la narrativa latinoamericana. México: Fondo de Cultura Económica.

Palma, R. (1961). Tradiciones peruanas. Madrid: Aguilar.

Reyes, R. (2013). "Ricardo Palma, precursor de la narrativa no ficcional" en Aula Palma, 12, 147-159. Lima: Editorial Universitaria de la Universidad Ricardo Palma.

Recibido el 7 de noviembre de 2019

Aprobado el 12 de noviembre de 2019 